Article

\title{
Quantum-Inspired Interpretable AI-Empowered Decision Support System for Detection of Early-Stage Rheumatoid Arthritis in Primary Care Using Scarce Dataset
}

\author{
Samira Abbasgholizadeh Rahimi ${ }^{1,2, *(\mathbb{D})}$, Mojtaba Kolahdoozi ${ }^{3}$, Arka Mitra ${ }^{4}\left(\mathbb{D}\right.$, Jose L. Salmeron ${ }^{5,6}(\mathbb{D}$, \\ Amir Mohammad Navali ${ }^{7}$, Alireza Sadeghpour ${ }^{7}$ and Seyed Amir Mir Mohammadi ${ }^{1}$ \\ 1 Department of Family Medicine, McGill University, Montreal, QC H3A 0G4,Canada; amir_mir8@yahoo.com \\ 2 Mila-Quebec AI Institute, Montreal, QC H2S 3H1, Canada \\ 3 Department of Electrical Engineering, Iran University of Science and Technology, Tehran 1311416846, Iran; \\ mojtabakolahdoozi@gmail.com \\ 4 Department of Electronics and Electrical Communication Engineering, Indian Institute of Technology \\ Kharagpur, Kharagpur 721302, India; thearkamitra@iitkgp.ac.in \\ 5 Data Science Lab, Universidad Pablo de Olavide, Ctra. de Utrera km. 1, 41013 Sevilla, Spain; \\ salmeron@acm.org \\ 6 Universidad Autónoma de Chile, 5 Poniente, Talca 1670, Chile \\ 7 Tabriz University of Medical Sciences \& Orthopedic Surgery Department, Shohada Medical Research \& \\ Training Hospital, East Azerbaijan, Tabriz 5165665931, Iran; amirmnavali@gmail.com (A.M.N.); \\ sadeghpoura46@yahoo.com (A.S.) \\ * Correspondence: samira.rahimi@mcgill.ca
}

Citation: Rahimi, S.A.; Kolahdoozi, M.; Mitra, A.; Salmeron, J.L.; Navali, A.M.; Sadeghpour, A.; Mir Mohammadi, S.A. Quantum-Inspired Interpretable AI-Empowered Decision Support System for Detection of Early-Stage Rheumatoid Arthritis in Primary Care Using Scarce Dataset. Mathematics 2022, 10, 496. https://doi.org/10.3390/ math10030496

Academic Editor: Jan Sładkowski

Received: 8 September 2021

Accepted: 5 January 2022

Published: 3 Februrary 2022

Publisher's Note: MDPI stays neutral with regard to jurisdictional claims in published maps and institutional affiliations.

Copyright: (C) 2022 by the authors. Licensee MDPI, Basel, Switzerland. This article is an open access article distributed under the terms and conditions of the Creative Commons Attribution (CC BY) license (https:// creativecommons.org/licenses/by/ $4.0 /)$.

\begin{abstract}
Rheumatoid arthritis (RA) is a chronic inflammatory and long-term autoimmune disease that can lead to joint and bone erosion. This can lead to patients' disability if not treated in a timely manner. Early detection of RA in settings such as primary care (as the first contact with patients) can have an important role on the timely treatment of the disease. We aim to develop a web-based Decision Support System (DSS) to provide a proper assistance for primary care providers in early detection of RA patients. Using Sparse Fuzzy Cognitive Maps, as well as quantum-learning algorithm, we developed an online web-based DSS to assist in early detection of RA patients, and subsequently classify the disease severity into six different levels. The development process was completed in collaborating with two specialists in orthopedic as well as rheumatology orthopedic surgery. We used a sample of anonymous patient data for development of our model which was collected from Shohada University Hospital, Tabriz, Iran. We compared the results of our model with other machine learning methods (e.g., linear discriminant analysis, Support Vector Machines, and K-Nearest Neighbors). In addition to outperforming other methods of machine learning in terms of accuracy when all of the clinical features are used (accuracy of $69.23 \%$ ), our model identified the relation of the different features with each other and gave higher explainability comparing to the other methods. For future works, we suggest applying the proposed model in different contexts and comparing the results, as well as assessing its usefulness in clinical practice.
\end{abstract}

Keywords: artificial intelligence; interpretable machine learning; fuzzy cognitive maps; rheumatoid arthritis; particle swarm optimization

\section{Introduction}

The Importance of Early Diagnosis of Rheumatoid Arthritis in Primary Care

Rheumatoid arthritis (RA) is an autoimmune, chronic inflammatory disease $[1,2]$. One can characterize the disease by persistent synovitis, systemic inflammation, and autoantibodies (particularly to rheumatoid factor and citrullinated peptide) [3]. The incidence of RA ranges between $0.5 \%$ to $1 \%$, and is more common among women and older adults [3]. Aside from the social burden, RA carries a substantial individual burden, resulting in 
"musculoskeletal deficits, with attendant decline in physical function, quality of life, and cumulative comorbid risk" [4].

Primary care physicians can contribute to improved outcomes of RA patients [1]. Primary care, is the gateway into the health care system for all needs and problems and all conditions, including uncommon or unusual ones such as RA $[5,6]$. Primary care providers are expected to recognize RA patients as early as possible and refer them to a rheumatologist [7]. Early diagnosis of RA, and consequently early treatment, are essential to better management of RA and may lead to reduce bone tissue loss and increase favorable outcomes, including remission [3,8,9]. However, diagnosis of RA is complex and difficult, and in many patients, early diagnosis is not possible given that clinical indicators are not specific to RA. Indeed, in the early stages of the disease, the typical RA patient has "tender and swollen joints of recent onset, morning joint stiffness, and abnormal laboratory tests, such as elevated concentrations of C-reactive protein or erythrocyte sedimentation rate" [3] which can be indicative of RA or other types of arthritis (e.g., reactive arthritis, osteoarthritis, psoriatic arthritis, infectious arthritis, or rarer autoimmune conditions such as connective tissue diseases) [3].

Our team's literature review showed that among over thousands of the studies only about 90 studies focus on AI in primary care, and among those only two studied the use of AI for diagnosis of RA [10]. Primary care providers need to have reliable RA diagnostic tools, as its early diagnosis could reduce the negative impact. The goal of this study is to develop an interpretable intelligent decision support system based on specialists knowledge (i.e., rheumatologists and orthopedic surgeons).

We organize the rest of this paper as following: Section 2.1 explains some of the previous studies focusing on diagnosis of RA, Sections 2.1-2.4 describes briefly the different methods we utilized and the previous work by those methods, Section 3.1 gives details about the dataset that we used in our study, Section 3.2 provides the description of the proposed algorithm, Section 4 contains the results of the proposed algorithm and comparison with other algorithms, Section 5 highlights the limitations of the this study and Section 6 concludes the paper.

\section{Background}

\subsection{Previous Works on Diagnosis of $R A$}

In the previous work [11], we designed a RA diagnosis decision support system by training a 10-node fully-connected Fuzzy Cognitive Map (FCM) and using a particle swarm optimization (PSO) algorithm. Morita et al. [12] proposed a finger joint detection method for RA diagnosis using 45 Japanese RA patients $X$-ray images, and support vector machines (SVM). Singh et al. [13] used human knowledge as rules for fuzzy logic controller (FLC) for diagnosis of RA, and Montejo et al. [14] used optical tomography images, extracted 594 features from the images, and using five different classifiers, classified images of RA patients.

Despite the attempts, some improvements are still needed in this area: (a) The previous works introduced fully connected networks. Those models have a high number of parameters, so it is possible for the model to memorize the different samples that it is trained on. This can increase the chance of overfitting due to increase in complexity of the network [15] and can decrease the ability of both explainability and static analysis of the network. (b) Previous works have considered simple objective functions in their classification process, such as classification accuracy. Generalizability of the model is low when one is dealing with small datasets, such as the datasets used in the above-mentioned works. Additionally, accuracy might not be the best metric when the training data have an imbalance in the number of classes. Therefore, it is important to tackle this problem by defining the right objective function. In order to overcome the above-mentioned limitations, in this study we propose a novel method based on FCM and a quantum learning algorithm [16], to classify the severity of RA data into six different classes in a way that 
is more interpretable and generalizable. The outcome of the interest is detection of RA patients at early stages.

\subsection{Fuzzy Cognitive Maps}

Fuzzy Cognitive Maps have been developed by Kosko [17] and are based on cognitive maps theory [18]. Using causal models, they attempt to mimic human experts' cognitive processes in specific domains. FCM uses a number of concepts and the causal relationships existing between the features for modeling a system, which can be represented as a directed graph [19]. FCM includes $N_{n}$ concepts whose values can be shown as Equation (1).

$$
C=\left[C_{1} C_{2} \cdots C_{N_{n}^{2}}\right]
$$

where $C$ is a state vector and $C_{i} \epsilon[0,1]$ represents the value of the $i$ th concept. As the value of a concept approaches +1 , its associated activation degree increases. The causal relationship of concepts can be stated in terms of a weight matrix, shown in the Equation (2).

$$
W=\left[\begin{array}{ccc}
w_{11} & \cdots & w_{1 n} \\
\cdot & \cdot & \cdot \\
\cdot & \cdot & \cdot \\
w_{n 1} & \cdots & w_{n n}
\end{array}\right]
$$

where $w_{i j} \epsilon[-1,+1]$ shows the value of a weight from the $i$ th to the $j$ th concept. When $w_{i j}$ is a positive number, the $i$ th concept has a positive impact on the $j$ th concept. In other words, any increase in the $i$ th concept results in an increase in the $j$ th concept. The $i$ th concept has a negative impact on the $j$ th concept when $w_{i j}$ is a negative number. In the case of $w_{i j}=0$, there is no causal relationship between the $i$ th and $j$ th concepts [19]. If $\mathrm{A}$ is causally related to $\mathrm{B}$, it does not necessarily mean that $\mathrm{B}$ is caused by $\mathrm{A}$ as well. Thus, $w_{i j}$ do not need to be equal to $w_{j i}$. In other words, the weight matrix does not need to be a symmetric matrix. Figure 1 shows a 4-node FCM with its associated weight matrix.

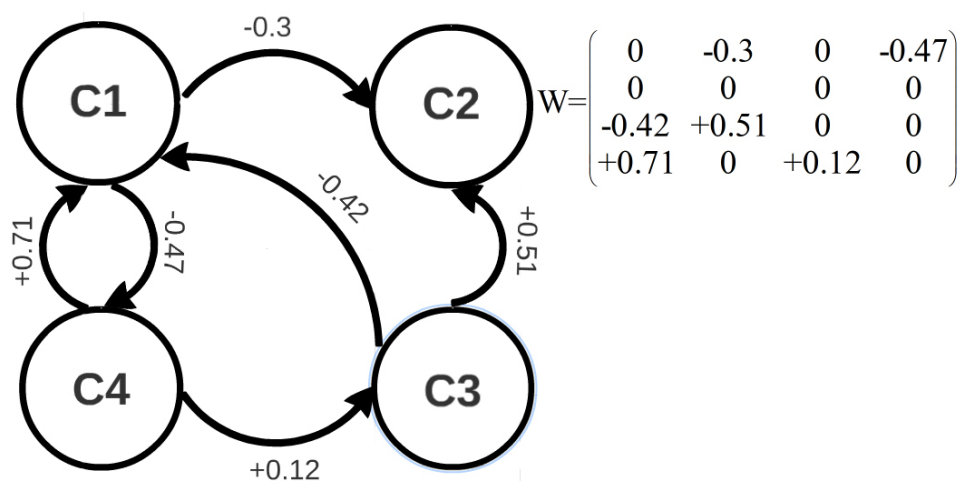

Figure 1. A 4-node FCM with its weight matrix.

The $i$ th node value in the $(t+1)$ th iteration can be calculated from the weight matrix and the values of the concepts in the $t$ th iteration. By using Equation (3), we can obtain:

$$
C_{i}(t+1)=\Psi\left(\sum_{j=1}^{N_{n}} w_{i j} C_{j}(t)\right)
$$

where $\Psi(x)$ is a transfer function, and is for limiting the output of the concept values to the desired range. Based on the conducted experiments [20], sigmoid transfer functions outperform other types of transfer functions; hence, we used this function, as stated in the Equation (4).

$$
\Psi(x)=\frac{1}{1+e^{-\lambda x}}
$$


where $\lambda$ is a free parameter which denotes the function's slope. A typical value of $\lambda$ is 5 [21]. Consider the Equation (3) in terms of a matrix multiplication:

$$
C(t+1)^{T}=\Psi\left(W * C(t)^{T}\right)
$$

where $A(t)^{T}$ represents the transpose of matrix $\mathrm{A}$ at $t$ th iteration.

The Equation (5) illustrates that, in every iteration, a FCM calculates the linear combination of row vectors, denoted by

$$
w_{i}=\left[w_{i 1} w_{i 2} \cdots w_{i n}\right],
$$

each with the $C_{i}$ coefficient and does a transformation to keep the values in the desired range. Owing to the use of a continuous transfer function, a FCM simulation can reach one of the following three cases [22]: (1) "Fixed point attractor" where after a limited number of iterations, all concepts converge to a fixed pattern; (2) "Limit cycle", where after a number of iterations, all concepts will fluctuate between a limited number of fixed patterns; and (3) "Chaotic attractor" where concepts will fluctuate between an unlimited number of patterns. Figure 2 shows a fixed-point attractor simulation for the FCM shown in Figure 1.

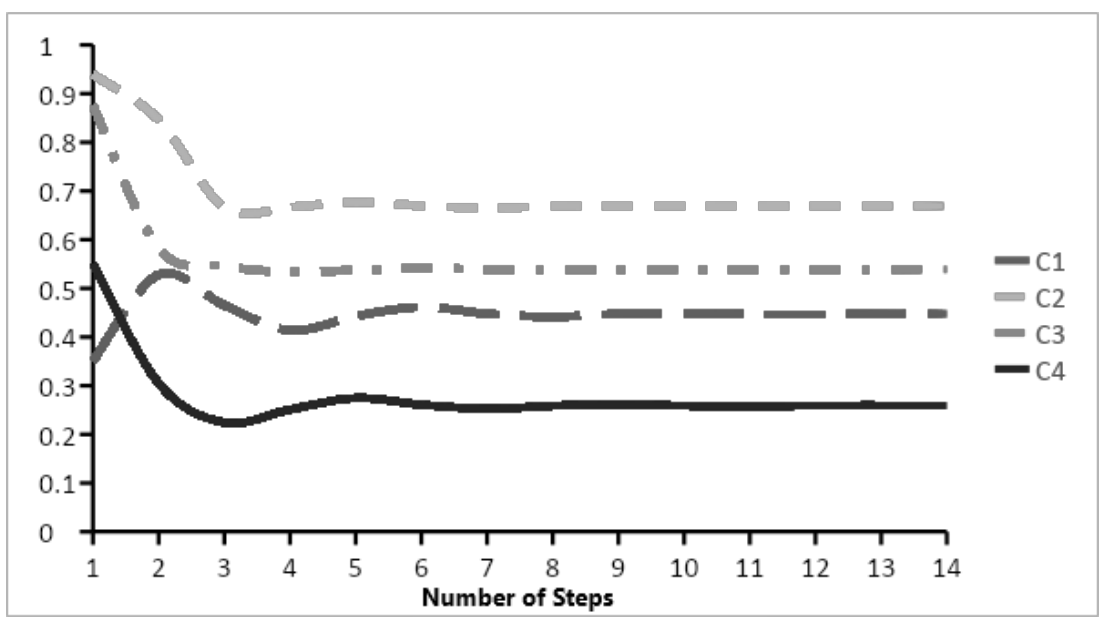

Figure 2. Fixed point simulation for the FCM shown in Figure 1.

\subsection{Particle Swarm Optimization}

Kennedy and Eberhart [23] introduced Particle Swarm Optimization (PSO) based on behavior observed in nature. It is one of the most popular optimization algorithms and used in various different fields, such as finance [24], chemistry [25], and medicine [26]. PSO is a search algorithm, which is based on population concept, where the particles comprising the population move in the multi-dimensional space to find the optimal position that optimizes an objective function. Based on the values returned by the objective function at each iteration, the gbest is the position which returns the global best value over all iterations and $p_{b e s t} t_{i}$ is the position having the best value of the $i$ th particle over all iterations.

The $i$ th position in a d-dimensional search space, denoted by

$$
x_{i}=\left[x_{i}^{1}, x_{i}^{2}, \ldots x_{i}^{d}\right],
$$

move towards a position in between the gbest and pbest $t_{i}$, guided by velocity $v_{i}$ which is also a d-dimensional vector. The whole update equations are given in Equations (6) and (7).

$$
\begin{gathered}
x_{i}(t+1)=v_{i}(t+1)+x_{i}(t) \\
v_{i}(t+1)=\omega v_{i}(t)+c_{1} r_{1}\left(\text { pbest }_{i}-x_{i}(t)\right)+c_{2} r_{2}\left(\text { gbest }-x_{i}(t)\right)
\end{gathered}
$$


where $\omega$ is a number chosen in the range of $[0.1,0.5]$ and $c_{1}, c_{2}$ are two numbers in the range of $[1.5,2]$. The values are chosen, such that PSO algorithm has a proper exploration and exploitation abilities at the same time. More exploration causes the particles to not converge to an optima. Although having a lot of exploitation would make the particles become stuck in a local optima, as they are not able to explore most of the search space.

\subsection{The QFCM Algorithm}

Fuzzy cognitive maps can be analyzed in two different ways: dynamic and static analysis. In dynamic analysis, values that are obtained from a FCM simulation, and the discrepancies between them and the test pattern are important. In static analysis, the weights, or lack of it, are important. Non-zero weights in FCM represent a causal relationship between concepts, in contrast to conventional neural networks such as multilayer perceptron (MLP).

Designing algorithms which can form a FCM with both dynamic and static analyses abilities is not an easy task and even conventional algorithms such as Non-linear Hebbian Learning (NHL) [27] are not able to do so. Recently, we proposed QFCM algorithm [16] to tackle this problem. It outperformed some other newly developed algorithms such as dMAGA [28]. The foundation of the QFCM algorithm is that it models the existence of a weight as a Q-bit. Q-bits are information units in the quantum evolutionary algorithm (QEA) [29], and models the values of weights as particles, which are theunits of information in PSO algorithm. Equation (8) shows a simple Q-bit.

$$
Q_{i}=\left[\begin{array}{l}
\alpha_{i} \\
\beta_{i}
\end{array}\right]
$$

In Equation (8), $\alpha_{i}^{2}$ and $\beta_{i}^{2}$ denote the probability that $Q_{i}$ exists (i.e., one state), and does not exist (i.e., zero state). We combine the quantum evolutionary algorithm (QEA) and particle swarm optimization (PSO) algorithm, such that the FCMs whose training is performed by QFCM, not only contain the causal relationship between the components but also can be analyzed dynamically or statically. One of the limitations of the QFCM is that it was developed for time series predictions. It is, therefore, not currently appropriate for classification problems. In this study, we overcame this limitation.

\section{Materials and Methods}

In this paper, we report our method development and validation according to the multivariable prediction model's transparent reporting for individual prognosis or diagnosis (TRIPOD) guideline. The TRIPOD guideline is used to help the authors in writing reports and help the readers to critically look at the different sections of the report [30]. The guideline of TRIPOD has been offered to support authors in writing reports of development and validation of their prediction models. See Appendix A for the TRIPOD checklist.

\subsection{Dataset}

To develop our web-based decision support system (DSS), we used a dataset with the information of 13 anonymous patients with RA who were randomly chosen from Shohada University Hospital in 2016. Table 1 shows the features that are used in the study along with the justification for their use. Table 2 shows some samples from the dataset and their associated severity or class label. We included all adults diagnosed with RA. The dataset has been used for training and validating. A subset of this dataset had been used for regression [11]. As with all artificial intelligence (AI) and machine learning (ML) empowered systems, the output of our DSS is highly related to the data with which it has been developed (input data). Given the complex and ambiguous nature of patient data, including clinical judgements, healthcare professionals may find it easier to express these data using linguistic variables rather than numerical ones [31]. In AI, fuzzy logic can help deal with these ambiguous, subjective, and imprecise judgments. Therefore, with the physicians, we chose six fuzzy variables with Gaussian membership functions (Extremely 
Severe, Very Severe, Severe, Minor, Very Minor, Extremely Minor) to describe the RA diagnostic criteria. The criteria and justifications for their selection are provided in Table 1. For further discussion regarding the selection of these criteria, refer to [11].

Table 1. Criteria for diagnosis of patients with RA and their explanations.

\begin{tabular}{|c|c|}
\hline Selected Criteria & Justification \\
\hline C1: Rest pain & $\begin{array}{l}\text { Pain is one the most common symptoms in patients with RA. While } \\
\text { it is assumed to be interlinked with inflammation, in many cases, } \\
\text { despite controlling the inflammation, the FL pain persists }[32,33] \text {. }\end{array}$ \\
\hline C2: Morning stiffness & $\begin{array}{l}\text { This symptom is common among patients with RA. Clinical trials } \\
\text { have shown that the duration of this symptom is associated with } \\
\text { reduced quality of life [34]. }\end{array}$ \\
\hline $\begin{array}{l}\text { C3: Symmetry of joint } \\
\text { infection }\end{array}$ & $\begin{array}{l}\text { Symmetrical joint involvement is a hallmark of RA. Patients usually } \\
\text { have several infections in their joints [35]. }\end{array}$ \\
\hline C4: Redness & $\begin{array}{l}\text { Due to inflammation, joints may become red and warm in } \\
\text { comparison to FL the surrounding tissue [35]. }\end{array}$ \\
\hline C5: Body pain & $\begin{array}{l}\text { Patients with RA usually experience moderate and persistent pain } \\
\text { in their body [36]. }\end{array}$ \\
\hline C6: Swelling & One symptom of RA, synovitis, can cause swelling in the joints [37]. \\
\hline $\begin{array}{l}\text { C7: Positive Rheumatoid } \\
\text { factor }(R F) \text { test }\end{array}$ & $\begin{array}{l}\text { This test determines the amount of RF in one's blood. RFs, } \\
\text { produced by immune system, are a kind of proteins which are able } \\
\text { to destroy healthy tissue. In } 70-80 \% \text { of RA patients test positively } \\
\text { for RF. This test has a specificity of } 86 \% \text { [35]. }\end{array}$ \\
\hline $\begin{array}{l}\text { C8: Elevated Erythrocyte } \\
\text { sedimentation rate (ESR): }\end{array}$ & $\begin{array}{l}\text { It is a test which is able to determine the severity of inflammation } \\
\text { inside a body. It measures the pace at which erythrocytes falls. } \\
\text { Patients with RA usually have elevated ESR, owing to } \\
\text { hypergammaglobulinemia }[35,38] \text {. }\end{array}$ \\
\hline $\begin{array}{l}\text { C9: Positive Anti-cyclic } \\
\text { citrullinated peptide } \\
\text { antibody test (Anti-CCP) }\end{array}$ & $\begin{array}{l}57 \% \text { to } 66 \% \text { of RA patients have a positive-anti-CCP. } \\
\text { Positive-anti-CCP patients usually have more severe RA with poor } \\
\text { prognosis [35]. }\end{array}$ \\
\hline
\end{tabular}

Additionally, based on health professionals' opinions, we assigned six different severity levels to the patients with RA so that they can also help with a more subjective understanding. The levels for each of the conditions for each of the patients is taken and there were no missing data in our dataset. Some of the selected data from the initial dataset from the hospital is shown in Table 2 . The $C_{i}$ refers to the $C_{i}$ criteria which is defined in Table 1.

Table 2. Some of the dataset used in this study.

\begin{tabular}{lllllllllll}
\hline No. & C1 & C2 & C3 & C4 & C5 & C6 & C7 & C8 & C9 & Severity (Class Label) \\
\hline 1 & 0.85 & 0.7 & 0.5 & 0.3 & 0.5 & 0.7 & 0.7 & 0.7 & 0.7 & Extremely severe (5) \\
\hline 2 & 1.0 & 0.7 & 0.5 & 0.3 & 0.5 & 0.7 & 0.7 & 0.7 & 0.7 & Extremely severe (5) \\
\hline 3 & 0.5 & 0.7 & 0.5 & 0.3 & 0.5 & 0.3 & 0.3 & 0.5 & 0.5 & Very severe (4) \\
\hline 4 & 0.7 & 0.5 & 0.5 & 0.3 & 0.5 & 0.3 & 0.7 & 0.7 & 0.3 & Very severe (4) \\
\hline & & & & & $\vdots$ & & & & & \\
\hline 10 & 0.15 & 0.15 & 0.15 & 0.3 & 0.15 & 0.5 & 0.3 & 0.5 & 0.3 & Very minor (1) \\
\hline 11 & 0.0 & 0.15 & 0.15 & 0.0 & 0.15 & 0.15 & 0.15 & 0.5 & 0.15 & Very minor (1) \\
\hline 12 & 0.15 & 0.0 & 0.15 & 0.0 & 0.15 & 0.15 & 0.0 & 0.3 & 0.15 & Extremely minor (0) \\
\hline 13 & 0.0 & 0.0 & 0.15 & 0.0 & 0.15 & 0.15 & 0.0 & 0.3 & 0.15 & Extremely minor (0) \\
\hline
\end{tabular}




\subsection{Proposed Method}

Our proposed method includes the training of a FCM with our QFCM algorithm [16] modified for classification problems and with a new objective function. The modified version of QFCM algorithm is a supervised learning methodology, that is presented in in Algorithm 1.

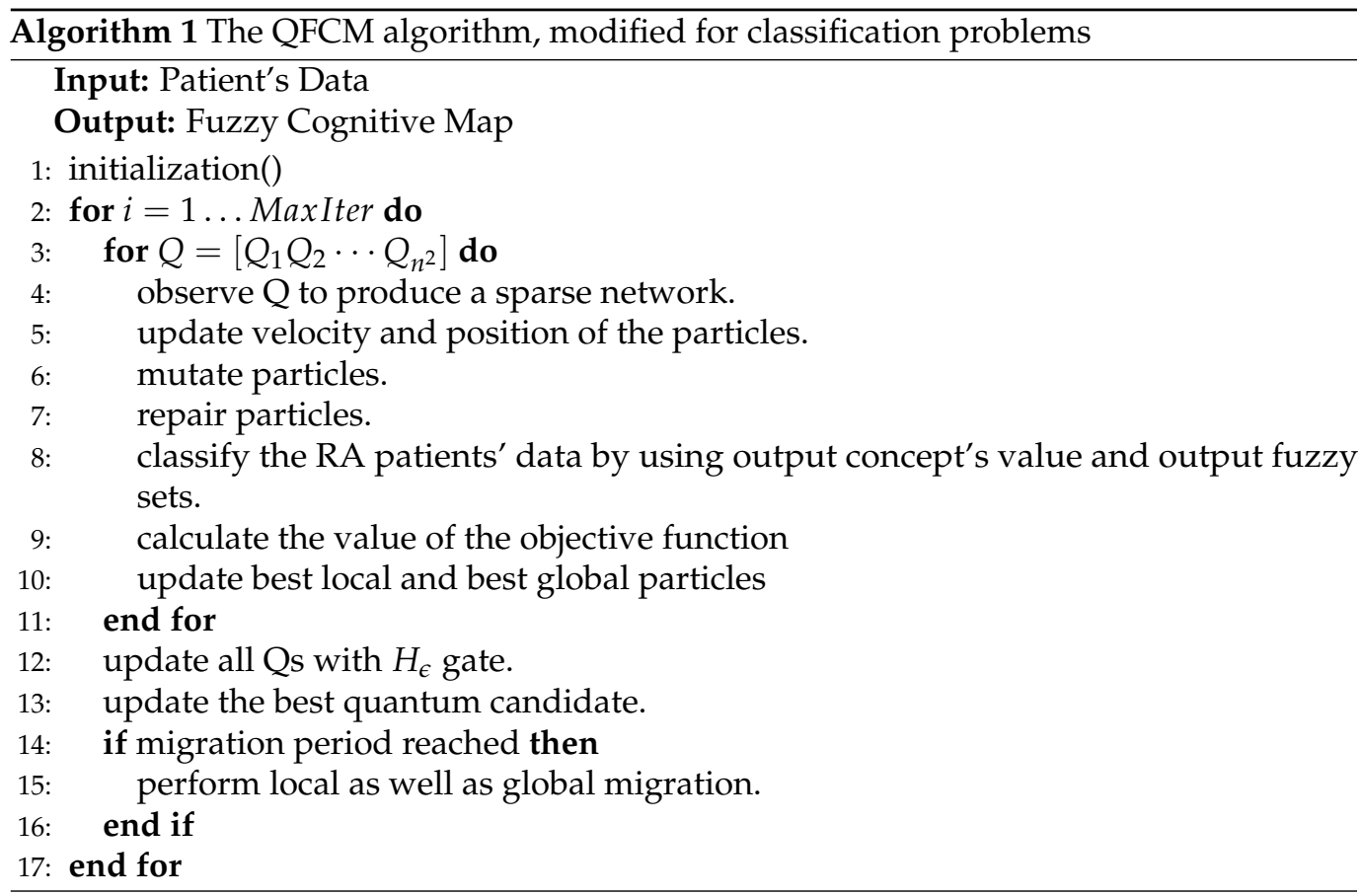

In the initialization phase, all the Q-bits within a quantum population consist of the training set are initialized with a value of $\frac{1}{\sqrt{2}}$ so that the probability of existence and inexistance of the links becomes equal, i.e., $\alpha_{i}=\beta_{i}=\frac{1}{\sqrt{2}}$ for all values of $i$. The positions and velocities of particles, representing the numerical values of weights, are initialized with a random number ranging between $[-1,-0.05)$ and $(+0.05,+1]$ and 0 , respectively. The range of $[-0.05,+0.05]$ is omitted because it cannot represent a causal relationship in a FCM [38]. In the observation process, either 1 (i.e., existence of a link) or 0 (i.e., inexistence of a link) is assigned to the Q-bits, based on the Equation (9).

$$
\operatorname{Bit}\left(Q_{i}\right)= \begin{cases}1, & \text { if } r>\alpha_{i}^{2} \\ 0, & \text { otherwise }\end{cases}
$$

In Equation (9), $r_{i}$ is a random number in the range of $[0,1]$ with uniform distribution. In the next step, the positions and velocities of the particles are updated according to the Equations (10) and (11), which are proposed in [39] as the modified version of the PSO algorithm.

$$
\begin{gathered}
p_{i}(t+1)=p_{i}(t)+v_{i}(t+1) \\
v_{i}(t+1)=\omega v_{i}(t)+c_{i} r_{i}\left(\text { lbest }_{i}(t)-p_{i}(t)\right) \\
+c_{2} r_{2}\left(\operatorname{gbest}(t)-p_{i}(t)\right)
\end{gathered}
$$

where $p_{i}(t)$ and $v_{i}(t)$ represent the position and velocity of the $i$ th particle at $t$ th iteration. $\omega, c_{1}$, and $c_{2}$ are three random numbers in the ranges of [0.1, 0.5], [1.5, 2], and [1.5, 2], respectively. "lbest $t_{i}$ " and "gbest" show the best positions of the $i$ th and of all particles, respectively. In step 6 of the QFCM algorithm, mutation occurs: elements from the latter half of each particle are sampled with a probability of $\mu$, and replaced with a random number in the range of $[-1,1]$. In the repair step (i.e., step 7 ), the values of all particles 
are confined to the range $[-1,+1]$ using Equation (12). It is worth noting that if $p_{i}$ is in the range $(+1,+\infty)$ or in the range $(-\infty,-1)$, the velocity of $i$ th particle is multiplied by -1 to reverse the search focus direction given that saturation has occurred in the initial direction. This ensures that the search algorithm does not explore areas that are outside the search space.

$$
\text { repair }\left(p_{i}\right)= \begin{cases}0, & \text { if } p_{i} \epsilon[-0.05,+0.05] \\ +1, & \text { if } p_{i} \epsilon(+1,+\mathrm{inf}) \\ -1, & \text { if } p_{i} \epsilon(-\mathrm{inf},-1) \\ p_{i}, & \text { otherwise }\end{cases}
$$

In the classification step 8, all of the trained samples are assigned to one of the six classes, illustrating the severity of RA. To this end, the value of the FCM's output concept is calculated for a given sample, as is the membership degree of this value in each of the six fuzzy sets (Figure 3). A sample is assigned to a class if its membership degree in this class is higher than that in the other classes. Centers and widths of the membership functions are design parameters.

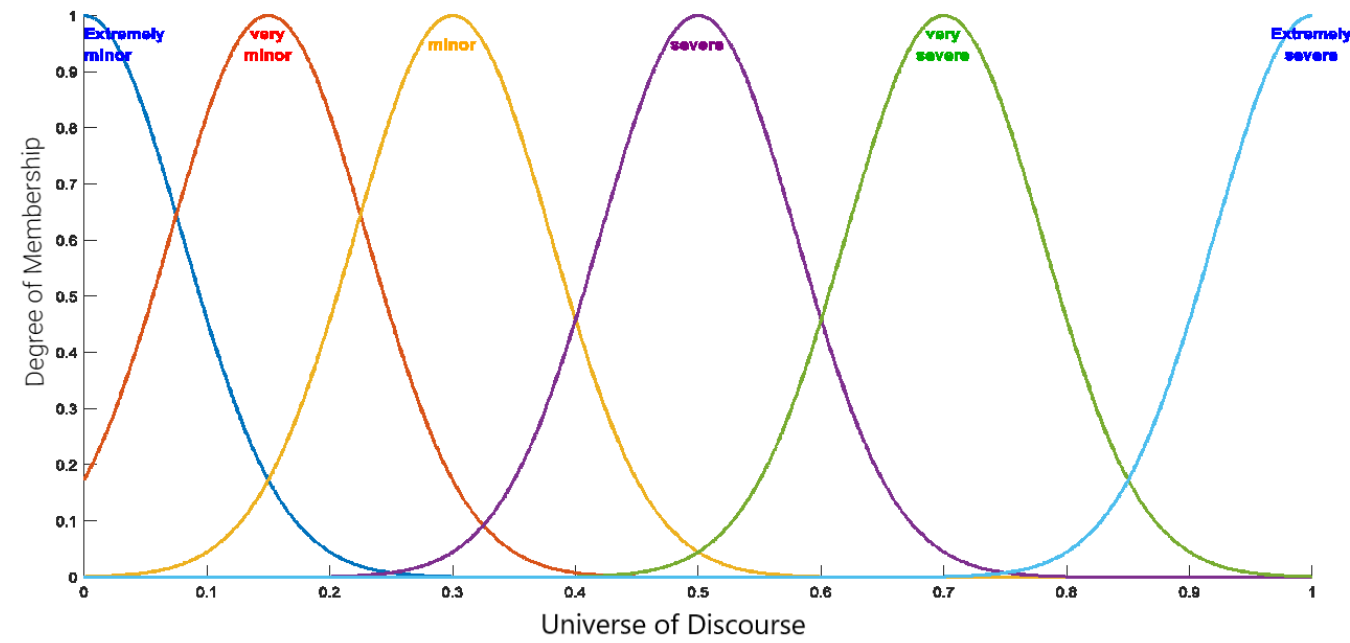

Figure 3. Membership functions associated with RA severity levels.

After the classification step, the output of objective function, proposed in this study in the context of FCMs, is calculated by Equation (13).

$$
F(w)=\frac{\# \text { misclassified }}{\# \text { samples }}+\sum_{i=1}^{\text {samples }} \frac{\left(x_{i}-b_{i}^{1}\right)^{2}+\left(x_{i}-b_{i}^{2}\right)^{2}}{N F}
$$

In Equation (13), "\#misclassified" is the total number of misclassified samples, "\#samples" is the total number of samples in the training set, $x_{i}$ is the value of the FCM output concept for the $i$ th sample in the training set, $b_{i}^{1}$ and $b_{i}^{2}$ are the two borders (i.e., intersection of fuzzy membership functions) nearest to $x_{i}$, and NF is the normalization factor that is defined in Equation (14). NF is defined in order to limit the second term of the objective function to the range of $[0,1]$.

$$
N F=\# \text { Samples } \times L b
$$

In Equation (14), Lb represents the length of the two farthest successive borders. As indicated by Equation (13), the objective function is designed in such a way that, apart from the classification accuracy, it considers the distance of the training samples from the borders. The global minimum of the second term of the objective function occurs when the FCM maps all the training samples, exactly, to the centers of the successive borders, placing them thus at the farthest possible distance from the borders. Therefore, according to the theory presented in the SVMs [40], the probability of generalizability increases. In 
step 10 of the QFCM algorithm, the best local and best global particles within the quantum population are saved. Subsequently, in step 12, the Q-bits are updated using H gate [41], which is defined in Equation (15).

$$
H_{\epsilon}\left(Q_{i}\right)= \begin{cases}{\left[\begin{array}{c}
\sqrt{\epsilon} \\
\sqrt{1-\epsilon}
\end{array}\right],} & \alpha^{2} \leq \epsilon \\
\operatorname{Rotate}\left(Q_{i}\right), & \epsilon<\alpha^{2} \leq 1-\epsilon \\
{\left[\begin{array}{c}
\sqrt{1-\epsilon} \\
\sqrt{\epsilon}
\end{array}\right],} & 1-\epsilon \leq \alpha^{2}\end{cases}
$$

In Equation (15), Rotate $\left(Q_{i}\right)$ indicates the rotation of the Q-bit by degrees, and the amount of rotation is a design parameter with the typical value of 0.01 . In step 15, local and global migration is performed as a mechanism for avoiding local optima. In this regard, values of the best quantum candidate are copied to other candidates locally or globally.

Fengmao et al. [42] showed that after several iterations, the Q-bit converges to either condition 1 or condition 3 of Equation (15). In previous studies [16], we proved that after convergence, it is difficult to escape from the optima it has converged into. Since this work is an extension to work for classification, the same reason applies and after several iterations, there is a low probability to escape from the local optima.

The new objective function defined in Equation (13) considers the predicted labels and the true data to assign values to each position. The modified QFCM algorithm is a supervised learning algorithm that classifies the severity of RA in the patient. For a new patient data, the attributes of the person is taken and the last attribute is taken to be $\frac{1}{\sqrt{2}}$. The attributes for the next iteration is obtained using Equation (5). The last attribute of the updated list can be mapped into the fuzzy membership function shown in Figure 3 to classify the patient into the different categories.

\section{Experimental Results}

In this section, we will first present the results of our analysis using the proposed method, as well as, the results of its comparison with other machine learning methods. Then, we will present the contribution of each of the diagnostic criteria to the results by illustrating the weight matrix obtained from training an FCM with our proposed method. For demonstrating the robustness of the proposed method against different parameter settings, we set the free parameters as shown in Table 3.

Table 3. Free parameters values of the proposed method.

\begin{tabular}{ccccc}
\hline MaxIter & Global Migration Period & Local Migration Period & $\boldsymbol{\epsilon}$ & $\boldsymbol{\mu}$ \\
\hline 1200 & 20 & 10 & 0.01 & 0.01 \\
\hline
\end{tabular}

\subsection{Classification Accuracy}

We trained a 10-node FCM, with one output concept, by using the data shown in the Table 2 and the proposed method. The dataset consists of 13 patients taken randomly from Shohada University Hospital. Considering the sample size, the selection of a reliable metric is important. For evaluating its efficacy, in view of the scarce dataset, we used leave-one-out cross validation method (LOOCV). Tables 4-12 shows the accuracy and confusion matrix obtained. Our modified QFCM algorithm (i.e., proposed method) classified nine of the 13 samples correctly, representing an accuracy rate of $69.23 \%$. Among the four misclassified samples, two belong to class 2, one belongs to class 1 , and one belongs to class 4 . In addition, based on the obtained confusion matrix, in three of the four misclassified samples, the predicted severity is higher than the actual severity. In other words, although misclassified, underdiagnosing of the patients with RA is avoided. In clinical contexts, false negatives are more dangerous than false positives. Overestimation of models leads to a false positive 
(i.e., overdiagnosis) rather than a false negative (i.e., underdiagnosis), therefore there will be a higher chance of the patient being asked to see a specialist.

In order to compare our results with other machine learning methods, we trained and evaluated different classifiers, namely linear discriminant analysis (LDA), linear SVM, quadratic SVM, cubic SVM, fine K nearest neighborhood (KNN), and weighted KNN_by LOOCV and using the same dataset (Table 2). To check the highest accuracy, we also tried to reduce the number of features and rerun the experiments. Since we are removing the search space, methods such as KNN are expected to perform better. However, based on domain knowledge (i.e., clinical literature and our collaborating specialists opinion), we observed that the removed features to increase accuracy are quite important in clinical experiments. Tables 4-12 present the results. The two models with fewer features had been checked to see if reducing the features would improve the accuracy or not. In one case, it does increase the accuracy but in cost of losing important clinical features which absolutely needs to be considered in this clinical context. Among the rest of the classifiers evaluated, LDA performed the best with an accuracy rate of $53.8 \%$, which is $15.4 \%$ lower than that of our QFCM (i.e., 69.23\%).

Moreover, unlike our proposed method, LDA underestimates the severity of RA, which may result in mis/under-diagnosis. Figure 4 presents a coweb [43] graphical representation of our proposed method and LDA to visually compare the two methods. It illustrates that the area under the curve for LDA is larger than the proposed method illustrating its lower accuracy. We randomly split the data into 5 folds, and QFCM plus LDA, linear SVM, Quadratic SVM, Cubic SVM, Fine KNN, and weighted KNN were trained on the data. We saved the obtained accuracy. We repeated this procedure for 10 times randomlyhaving sufficient accuracies to run statistical test. Then, we applied $t$-test. The following table shows the obtained $p$-values (Table 13). Given the results, the inference is that in all scenarios, there is a significant difference between the accuracies obtained by the proposed method, i.e., QFCM, and other methods. This testing proves that QFCM can significantly outperform other methods in terms of accuracy.

Table 4. Proposed Method. Accuracy: 69.23\%.

\begin{tabular}{|c|c|c|c|c|c|c|c|}
\hline \multicolumn{8}{|c|}{ Predicted } \\
\hline \multirow{7}{*}{ Actual } & & 0 & 1 & 2 & 3 & 4 & 5 \\
\hline & 0 & 2 & 0 & 0 & 0 & 0 & 0 \\
\hline & 1 & 0 & 1 & 1 & 0 & 0 & 0 \\
\hline & 2 & 0 & 0 & 0 & 0 & 2 & 0 \\
\hline & 3 & 0 & 0 & 0 & 2 & 0 & 0 \\
\hline & 4 & 0 & 0 & 0 & 1 & 2 & 0 \\
\hline & 5 & 0 & 0 & 0 & 0 & 0 & 2 \\
\hline
\end{tabular}

Table 5. Linear discriminant analysis (LDA). Accuracy: 53.8\%.

\begin{tabular}{llllllll}
\hline & \multicolumn{7}{c}{ Predicted } \\
\hline \multirow{5}{*}{ Actual } & & 0 & 1 & 2 & 3 & 4 & 5 \\
\cline { 2 - 8 } & 0 & 2 & 0 & 0 & 0 & 0 & 0 \\
\cline { 2 - 8 } & 1 & 1 & 0 & 1 & 0 & 0 & 0 \\
\cline { 2 - 8 } & 2 & 0 & 0 & 0 & 2 & 0 & 0 \\
\cline { 2 - 8 } & 3 & 0 & 0 & 1 & 0 & 1 & 0 \\
\cline { 2 - 8 } & 4 & 0 & 0 & 0 & 0 & 3 & 0 \\
\hline
\end{tabular}


Table 6. Linear SVM; Accuracy 15.4\%.

\begin{tabular}{llllllll}
\hline & \multicolumn{7}{c}{ Predicted } \\
\hline \multirow{5}{*}{ Actual } & & 0 & 1 & 2 & 3 & 4 & 5 \\
\cline { 2 - 8 } & 0 & 0 & 2 & 0 & 0 & 0 & 0 \\
\cline { 2 - 8 } & 1 & 1 & 0 & 1 & 0 & 0 & 0 \\
\cline { 2 - 8 } & 2 & 0 & 0 & 0 & 1 & 1 & 0 \\
\cline { 2 - 8 } & 3 & 0 & 0 & 1 & 0 & 1 & 0 \\
\cline { 2 - 8 } & 4 & 0 & 0 & 1 & 0 & 2 & 0 \\
\hline
\end{tabular}

Table 7. Quadratic SVM; Accuracy 46.2\%.

\begin{tabular}{llllllll}
\hline \multicolumn{7}{c}{ Predicted } \\
\hline \multirow{5}{*}{ Actual } & \multicolumn{1}{c}{0} & 1 & 2 & 3 & 4 & 5 \\
\cline { 2 - 8 } & 0 & 2 & 0 & 0 & 0 & 0 & 0 \\
\cline { 2 - 8 } & 1 & 1 & 1 & 0 & 0 & 0 & 0 \\
\cline { 2 - 8 } & 2 & 0 & 0 & 0 & 2 & 0 & 0 \\
\cline { 2 - 8 } & 3 & 0 & 0 & 2 & 0 & 0 & 0 \\
\hline & 4 & 0 & 0 & 1 & 1 & 1 & 0 \\
\hline
\end{tabular}

Table 8. Cubic SVM; Accuracy 38.5\%.

\begin{tabular}{|c|c|c|c|c|c|c|c|}
\hline \multicolumn{8}{|c|}{ Predicted } \\
\hline \multirow{7}{*}{ Actual } & & 0 & 1 & 2 & 3 & 4 & 5 \\
\hline & 0 & 2 & 0 & 0 & 0 & 0 & 0 \\
\hline & 1 & 1 & 0 & 1 & 0 & 0 & 0 \\
\hline & 2 & 0 & 0 & 0 & 2 & 0 & 0 \\
\hline & 3 & 0 & 0 & 2 & 0 & 0 & 0 \\
\hline & 4 & 0 & 0 & 1 & 1 & 1 & 0 \\
\hline & 5 & 0 & 0 & 0 & 0 & 0 & 2 \\
\hline
\end{tabular}

Table 9. Fine KNN; Accuracy 46.2\%.

\begin{tabular}{|c|c|c|c|c|c|c|c|}
\hline \multicolumn{8}{|c|}{ Predicted } \\
\hline \multirow{7}{*}{ Actual } & & 0 & 1 & 2 & 3 & 4 & 5 \\
\hline & 0 & 2 & 0 & 0 & 0 & 0 & 0 \\
\hline & 1 & 1 & 1 & 0 & 0 & 0 & 0 \\
\hline & 2 & 0 & 0 & 0 & 1 & 1 & 0 \\
\hline & 3 & 0 & 0 & 2 & 0 & 0 & 0 \\
\hline & 4 & 0 & 0 & 1 & 1 & 1 & 0 \\
\hline & 5 & 0 & 0 & 0 & 0 & 0 & 2 \\
\hline
\end{tabular}

Table 10. Weighted KNN; Accuracy 46.2\%.

\begin{tabular}{|c|c|c|c|c|c|c|c|}
\hline \multicolumn{8}{|c|}{ Predicted } \\
\hline \multirow{7}{*}{ Actual } & & 0 & 1 & 2 & 3 & 4 & 5 \\
\hline & 0 & 2 & 0 & 0 & 0 & 0 & 0 \\
\hline & 1 & 1 & 0 & 1 & 0 & 0 & 0 \\
\hline & 2 & 0 & 0 & 0 & 1 & 1 & 0 \\
\hline & 3 & 0 & 0 & 1 & 0 & 1 & 0 \\
\hline & 4 & 0 & 0 & 1 & 0 & 2 & 0 \\
\hline & 5 & 0 & 0 & 0 & 0 & 0 & 2 \\
\hline
\end{tabular}


Table 11. KNN with 4 features; Accuracy $76.9 \%$.

\begin{tabular}{|c|c|c|c|c|c|c|c|}
\hline \multicolumn{8}{|c|}{ Predicted } \\
\hline \multirow{7}{*}{ Actual } & & 0 & 1 & 2 & 3 & 4 & 5 \\
\hline & 0 & 2 & 0 & 0 & 0 & 0 & 0 \\
\hline & 1 & 0 & 2 & 0 & 0 & 0 & 0 \\
\hline & 2 & 0 & 0 & 0 & 2 & 0 & 0 \\
\hline & 3 & 0 & 0 & 0 & 1 & 1 & 0 \\
\hline & 4 & 0 & 0 & 0 & 0 & 3 & 0 \\
\hline & 5 & 0 & 0 & 0 & 0 & 0 & 2 \\
\hline
\end{tabular}

Table 12. KNN with 3 features; Accuracy $61.5 \%$.

\begin{tabular}{llllllll}
\hline & \multicolumn{7}{c}{ Predicted } \\
\hline \multirow{5}{*}{ Actual } & & 0 & 1 & 2 & 3 & 4 & 5 \\
\cline { 2 - 8 } & 0 & 2 & 0 & 0 & 0 & 0 & 0 \\
\cline { 2 - 8 } & 1 & 0 & 1 & 1 & 0 & 0 & 0 \\
\cline { 2 - 8 } & 2 & 0 & 0 & 0 & 0 & 2 & 0 \\
\cline { 2 - 8 } & 3 & 0 & 0 & 1 & 0 & 1 & 0 \\
\cline { 2 - 7 } & 5 & 0 & 0 & 0 & 0 & 0 & 2 \\
\hline
\end{tabular}
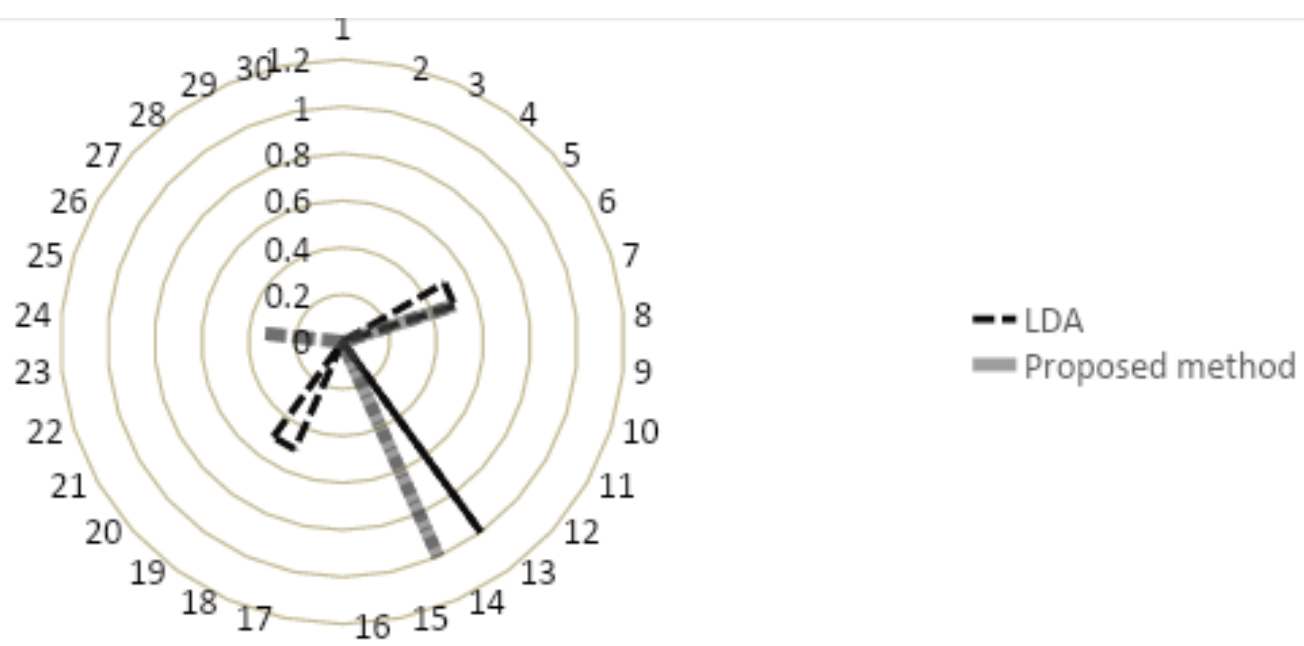

Figure 4. Cobweb graphical representation of LDA and our proposed method.

Table 13. $p$-values of the different algorithms.

\begin{tabular}{ccccccc}
\hline & LDA & $\begin{array}{c}\text { Linear } \\
\text { SVM }\end{array}$ & $\begin{array}{c}\text { Quadratic } \\
\text { SVM }\end{array}$ & $\begin{array}{c}\text { Cubic } \\
\text { SVM }\end{array}$ & $\begin{array}{c}\text { Fine } \\
\text { KNN }\end{array}$ & $\begin{array}{c}\text { Weighted } \\
\text { KNN }\end{array}$ \\
\hline QFCM & 0.002 & 0.005 & 0.001 & 0.006 & 0.002 & 0.002 \\
\hline
\end{tabular}

\subsection{Weight Matrix of the FCM and Its Interpretability}

Using our dataset (Table 2), we trained an FCM, with the weight matrix shown in Equation (16). The density of this FCM is 50\%, meaning that half of the 100 weights are zero. The first nine columns represent the nine criteria in the order presented in Table 1. Furthermore, an extra node has been added which is connected to all other nodes. This 10th node is used to determine the contribution of the other nodes to detect the disease. The 10th column of this matrix elucidates the impact of each of the features on the output concept. None of the weights of associated with RA diagnostic tests (i.e., C7, C8, C9) are 0 , demonstrating the importance of these tests relative to the physical symptoms of RA. 
Among the physical symptoms chosen for the diagnostic criteria, rest pain had the most important contribution to the output, whereas the weights of morning stiffness, redness, and body pain were zero and among lab tests, ESR had a greater impact on the output. Regarding anti-CCP and RF, our QFCM algorithm assigned a larger weight to anti-CCP, which indicates that it contributes more to the output than RF, which is compatible with the clinical study conducted on over 1025 patients [44].

$$
W=\left[\begin{array}{cccccccccc}
-0.906 & 0 & 0 & 0 & 0 & -0.774 & -0.068 & 0 & -0.058 & -0.930 \\
0 & -0.283 & 0 & 0 & 0 & 0.799 & -0.999 & -0.360 & 0 & 0 \\
-0.707 & 0 & 0 & -0.130 & -0.706 & 0 & 0 & -0.326 & -0.839 & -0.313 \\
0.137 & 0 & 0.869 & 0.889 & -0.978 & -0.512 & -0.332 & 0 & -0.614 & 0 \\
0 & -0.738 & 0 & 0 & 0.375 & 0.954 & 0 & 0.749 & 0 & 0 \\
-0.292 & -0.824 & 0.778 & 0 & 0 & 0 & 0 & 0 & 0.852 & 0.647 \\
-0.612 & 0.416 & 0 & 0 & 0 & 0 & 0 & -0.215 & -0.275 & -0.616 \\
0.869 & -0.937 & 0 & 0 & -0.735 & 0 & 0 & -0.877 & 0 & -0.999 \\
0 & 0 & 0 & 0.945 & 0.393 & 0.444 & 0 & -0.484 & 0 & 0.623 \\
1 & 0 & 0 & -0.403 & -0.787 & 0 & 0 & 0 & 0.447 & 0
\end{array}\right]
$$

Using the Equation (16), the interactions between the criteria can be investigated. Weights with values near to 1 or -1 are indicative of strong relationships. For example, referring to the first column on the left, if we ignore the self-feedback/loop, our results indicate that ESR (i.e., C9) is the criterion most strongly related to rest pain (i.e., C1) and symmetry of joint infection (i.e., C3), or according to the 5th column from the left, body pain and redness (i.e., C5 and C4) are interlinked.

\subsection{Web Based DSS}

Our DSS is freely available for academic purposes and can be accessed from the GitHub page https: / github.com/rahimi-s-lab / RA-paper (accessed on 1 December 2021) or https: / / rahimislab.ca/ra-dss (accessed on 1 December 2021) and is coded in the Hypertext Preprocessor (PHP) language to make it easy to use. To help calculate the severity of a RA patient, the input data should be inserted by a user for each of the nine diagnostic criteria (Figure 5). The DSS will perform all calculations based on the proposed method in this study and immediately display the patient's severity of RA along with interpretations of the results (Figure 6). The DSS also contains information on the symptoms and some information on RA. 


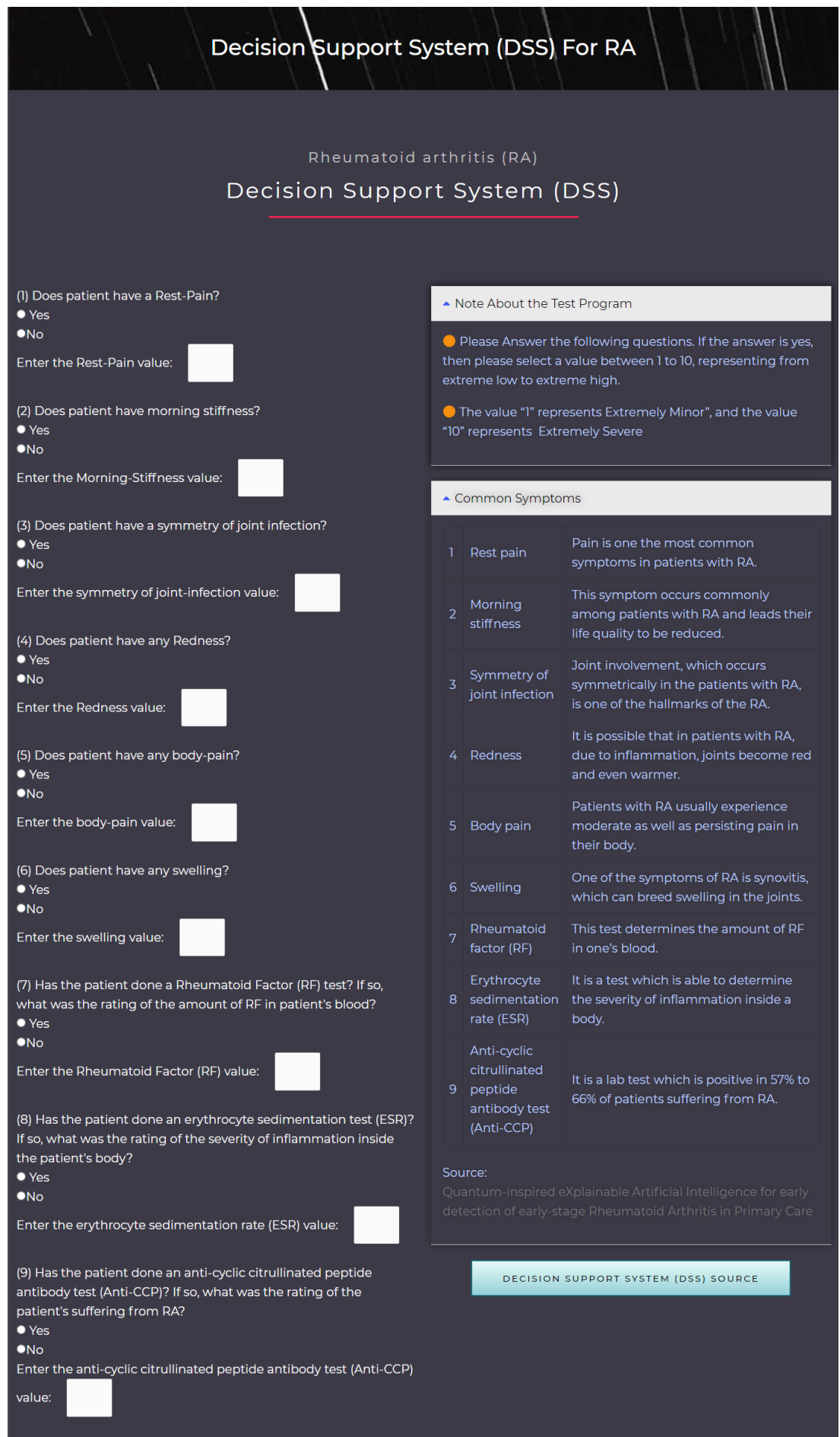

Figure 5. The DSS FL interface for taking user input.

Based on the evaluated value, the patient is in the category of:

Very Minor

Figure 6. The DSS interface for user output. 


\section{Limitations}

First, while we acknowledge the small sample size in our study, we believe this study is a good illustration of how hybrid interpretable AI methods could be developed with support of domain knowledge for early detection of diseases using small dataset. Second, the developed web based decision support system is not tested and/or validated with different users. Future studies are needed to evaluate end-users perspectives on the developed tool.

\section{Conclusions}

Primary care providers are responsible for identifying patients with RA and referring them to a specialist, however, the diagnosis of patients with RA is complex and, in many cases, early diagnosis of RA by primary care providers is not an easy task because of the non-specific nature of their symptoms and clinical indicators. The aim of this study was to: (1) contribute to the existing methodology in the field by overcoming the current limitations, and (2) develop a web-based Decision Support System to aid primary care providers in early diagnosis of patients with RA. We developed this system based on wellknown soft computing method, Fuzzy Cognitive Maps, and modified quantum learning algorithm. To develop the algorithm for this system, we consulted with two specialists (i.e., a rheumatologist and an orthopedic surgeon) and integrated their knowledge into our model. We evaluated the accuracy of the proposed method and compared its accuracy rate with other machine learning methods such as LDA, quadratic SVM, weighted KNN which had accuracies of $53.8 \%, 46.2 \%$ and $46.2 \%$, respectively. Our proposed hybrid method obtained the highest accuracy when all the features of interest are considered and outperformed other machine learning methods. Apart from having higher accuracy, one of the strengths of our proposed hybrid method is its interpretability. Due to the FCM matrix generated, one can obtain an idea of how the different features are related to each other and contribute to the final output. For the future works, more investigations are required to evaluate the developed method and web-based decision support system in larger-scale, adapt it to other clinical contexts, and interlink the knowledge obtained from the interpretability of the network into human knowledge.

Author Contributions: Data curation, A.M.N. and A.S.; Methodology, M.K. and A.M.; Supervision, S.A.R. and J.L.S.; Visualization, S.A.M.M.; Writing—original draft, M.K.; Writing—review \& editing, A.M. All authors have read and agreed to the published version of the manuscript.

Funding: This study was funded by Natural Sciences and Engineering Research Council (NSERC) Discovery (grant 2020-05246) (Principal Investigators [PI]: SAR), and start-up fund from McGill University (PI: SAR). We acknowledge the support from these institutions.

Institutional Review Board Statement: Not applicable.

Informed Consent Statement: Not applicable.

Data Availability Statement: Not applicable.

Acknowledgments: S.A.R. is funded by a Research Scholar Junior 1 Career Development Award by the Fonds de Recherche du Québec-Santé (FRQS), and her research program is supported by Natural Sciences and Engineering Research Council (NSERC) Discovery Grant \#2020-05246. The authors would like to thank the physicians who labelled the data, as well as, Shohada University Hospital for their contribution.

Conflicts of Interest: The authors declare no conflicts of interest.

\section{Appendix A}

Transparent Reporting of a Multi-Variable Prediction Model for Individual Prognosis or Diagnosis (TRIPOD) Checklist. 
Table A1. TRIPOD Checklist.

\begin{tabular}{|c|c|c|c|c|}
\hline Section/Topic & Item & & Checklist Item & Page \\
\hline \multicolumn{5}{|c|}{ Title and Abstract } \\
\hline Title & 1 & $\mathrm{D} ; \mathrm{V}$ & $\begin{array}{l}\text { Identify the study as developing and/or validating a multi-variable } \\
\text { prediction model, the target population, and the outcome to } \\
\text { be predicted }\end{array}$ & 1 \\
\hline Abstract & 2 & $\mathrm{D} ; \mathrm{V}$ & $\begin{array}{l}\text { Provide a summary of objectives, study design, setting, participants, } \\
\text { sample size, predictors, outcome, statistical analysis, results, } \\
\text { and conclusions. }\end{array}$ & 1 \\
\hline \multicolumn{5}{|l|}{ Introduction } \\
\hline \multirow[t]{2}{*}{$\begin{array}{l}\text { Background } \\
\text { and objectives }\end{array}$} & $3 a$ & $\mathrm{D} ; \mathrm{V}$ & $\begin{array}{l}\text { Explain the medical context (including whether diagnostic or } \\
\text { prognostic) and rationale for developing or validating the } \\
\text { multi-variable prediction model, including references to } \\
\text { existing models. }\end{array}$ & $\begin{array}{l}1,2,3,4 \\
5\end{array}$ \\
\hline & $3 b$ & $\mathrm{D} ; \mathrm{V}$ & $\begin{array}{l}\text { Specify the objectives, including whether the study describes the } \\
\text { development or validation of the model or both. }\end{array}$ & 2 \\
\hline \multicolumn{5}{|l|}{ Methods } \\
\hline \multirow{2}{*}{ Source of data } & $4 a$ & $\mathrm{D} ; \mathrm{V}$ & $\begin{array}{l}\text { Describe the study design or source of data (e.g., randomized trial, } \\
\text { cohort, or registry data), separately for the development and } \\
\text { validation datasets, if applicable. }\end{array}$ & 5,6 \\
\hline & $4 \mathrm{~b}$ & $\mathrm{D} ; \mathrm{V}$ & $\begin{array}{l}\text { Specify the key study dates, including start of accrual; end of } \\
\text { accrual; and, if applicable, end of follow-up. }\end{array}$ & 5,6 \\
\hline \multirow[t]{3}{*}{ Participants } & $5 a$ & $\mathrm{D} ; \mathrm{V}$ & $\begin{array}{l}\text { Specify key elements of the study setting (e.g., primary care, } \\
\text { secondary care, general population) including number and location } \\
\text { of centres. }\end{array}$ & 5,6 \\
\hline & $5 b$ & $\mathrm{D} ; \mathrm{V}$ & Describe eligibility criteria for participants. & 5 \\
\hline & $5 c$ & $\mathrm{D} ; \mathrm{V}$ & Give details of treatments received, if relevant & 6 \\
\hline \multirow{2}{*}{ Outcome } & $6 a$ & $\mathrm{D} ; \mathrm{V}$ & $\begin{array}{l}\text { Clearly define the outcome that is predicted by the prediction } \\
\text { model, including how and when assessed. }\end{array}$ & 10 \\
\hline & $6 \mathrm{~b}$ & $\mathrm{D} ; \mathrm{V}$ & $\begin{array}{l}\text { Report any actions to blind assessment of the outcome to be } \\
\text { predicted }\end{array}$ & N.A. \\
\hline \multirow{2}{*}{ Predictors } & $7 \mathrm{a}$ & $\mathrm{D} ; \mathrm{V}$ & $\begin{array}{l}\text { Clearly define all predictors used in developing or validating the } \\
\text { multi-variable prediction model, including how and when they } \\
\text { were measured. }\end{array}$ & 6 \\
\hline & $7 \mathrm{~b}$ & $\mathrm{D} ; \mathrm{V}$ & $\begin{array}{l}\text { Report any actions to blind assessment of predictors for the } \\
\text { outcome and other predictors. }\end{array}$ & N.A. \\
\hline Sample size & 8 & $\mathrm{D} ; \mathrm{V}$ & Explain how the study size was arrived at. & N.A. \\
\hline Missing data & 9 & $\mathrm{D} ; \mathrm{V}$ & $\begin{array}{l}\text { Describe how missing data were handled (e.g., complete-case } \\
\text { analysis, single imputation, multiple imputation) with details of any } \\
\text { imputation method. }\end{array}$ & 6 \\
\hline \multirow{5}{*}{$\begin{array}{l}\text { Statistical } \\
\text { analysis } \\
\text { methods }\end{array}$} & $10 \mathrm{a}$ & $\mathrm{D}$ & Describe how predictors were handled in the analyses. & 6 \\
\hline & $10 \mathrm{~b}$ & $\mathrm{D}$ & $\begin{array}{l}\text { Specify type of model, all model-building procedures (including any } \\
\text { predictor selection), and method for internal validation. }\end{array}$ & $4,5,6$ \\
\hline & 10c & $\mathrm{V}$ & For validation, describe how the predictions were calculated. & 9 \\
\hline & $10 \mathrm{~d}$ & $\mathrm{D} ; \mathrm{V}$ & $\begin{array}{l}\text { Specify all measures used to assess model performance and, if } \\
\text { relevant, to compare multiple models. }\end{array}$ & $\begin{array}{l}9,10,11, \\
12\end{array}$ \\
\hline & $10 \mathrm{e}$ & $\mathrm{V}$ & $\begin{array}{l}\text { Describe any model updating (e.g., recalibration) arising from the } \\
\text { validation, if done. }\end{array}$ & N.A. \\
\hline Risk groups & 11 & $\mathrm{D} ; \mathrm{V}$ & Provide details on how risk groups were created, if done. & N.A. \\
\hline $\begin{array}{l}\text { Development } \\
\text { vs. validation }\end{array}$ & 12 & $\mathrm{~V}$ & $\begin{array}{l}\text { For validation, identify any differences from the development data } \\
\text { in setting, eligibility criteria, outcome, and predictors. }\end{array}$ & 9 \\
\hline
\end{tabular}


Table A1. Cont.

\begin{tabular}{|c|c|c|c|c|}
\hline Section/Topic & Item & & Checklist Item & Page \\
\hline \multicolumn{5}{|l|}{ Results } \\
\hline \multirow{3}{*}{ Participants } & $13 a$ & $\mathrm{D} ; \mathrm{V}$ & $\begin{array}{l}\text { Describe the flow of participants through the study, including the } \\
\text { number of participants with and without the outcome and, if } \\
\text { applicable, a summary of the follow-up time. A diagram may } \\
\text { be helpful. }\end{array}$ & N.A. \\
\hline & $13 b$ & $\mathrm{D} ; \mathrm{V}$ & $\begin{array}{l}\text { Describe the characteristics of the participants (basic demographics, } \\
\text { clinical features, available predictors), including the number of } \\
\text { participants with missing data for predictors and outcome. }\end{array}$ & N.A. \\
\hline & $13 c$ & $\mathrm{~V}$ & $\begin{array}{l}\text { For validation, show a comparison with the development data of } \\
\text { the distribution of important variables (demographics, predictors } \\
\text { and outcome). }\end{array}$ & N.A. \\
\hline \multirow{2}{*}{$\begin{array}{l}\text { Model } \\
\text { development }\end{array}$} & $14 \mathrm{a}$ & $\mathrm{D}$ & $\begin{array}{l}\text { Specify the number of participants and outcome events in each } \\
\text { analysis }\end{array}$ & $10,11,12$ \\
\hline & $14 \mathrm{~b}$ & $\mathrm{D}$ & $\begin{array}{l}\text { If done, report the unadjusted association between each candidate } \\
\text { predictor and outcome. }\end{array}$ & 12,13 \\
\hline \multirow[t]{2}{*}{$\begin{array}{l}\text { Model } \\
\text { specification }\end{array}$} & $15 a$ & $\mathrm{D}$ & $\begin{array}{l}\text { Present the full prediction model to allow predictions for } \\
\text { individuals (i.e., all regression coefficients, and model intercept or } \\
\text { baseline survival at a given time point). }\end{array}$ & 13,14 \\
\hline & $15 b$ & $\mathrm{D}$ & Explain how to the use the prediction model. & $9,13,14$ \\
\hline $\begin{array}{l}\text { Model } \\
\text { performance }\end{array}$ & 16 & $\mathrm{D} ; \mathrm{V}$ & Report performance measures (with CIs) for the prediction model. & 10 \\
\hline $\begin{array}{l}\text { Model- } \\
\text { updating }\end{array}$ & 17 & $\mathrm{~V}$ & $\begin{array}{l}\text { If done, report the results from any model updating (i.e., model } \\
\text { specification, model performance). }\end{array}$ & N.A. \\
\hline \multicolumn{5}{|l|}{ Discussion } \\
\hline Limitations & 18 & $\mathrm{D} ; \mathrm{V}$ & $\begin{array}{l}\text { Discuss any limitations of the study (such as non-representative } \\
\text { sample, few events per predictor, missing data). }\end{array}$ & 13 \\
\hline \multirow[b]{2}{*}{ Interpretation } & $19 a$ & $\mathrm{~V}$ & $\begin{array}{l}\text { For validation, discuss the results with reference to performance in } \\
\text { the development data, and any other validation data. }\end{array}$ & $10,11,12$ \\
\hline & $19 b$ & $\mathrm{D} ; \mathrm{V}$ & $\begin{array}{l}\text { Give an overall interpretation of the results, considering objectives, } \\
\text { limitations, results from similar studies, and other relevant } \\
\text { evidence. }\end{array}$ & $\begin{array}{l}10,11 \\
12,13\end{array}$ \\
\hline Implications & 20 & $\mathrm{D} ; \mathrm{V}$ & $\begin{array}{l}\text { Discuss the potential clinical use of the model and implications for } \\
\text { future research. }\end{array}$ & 14 \\
\hline \multicolumn{5}{|c|}{ Other Information } \\
\hline $\begin{array}{l}\text { Supplementary } \\
\text { information }\end{array}$ & 21 & $\mathrm{D} ; \mathrm{V}$ & $\begin{array}{l}\text { Provide information about the availability of supplementary } \\
\text { resources, such as study protocol, Web calculator, anddatasets. }\end{array}$ & $\begin{array}{l}13,14 \\
18,19\end{array}$ \\
\hline Funding & 22 & $\mathrm{D} ; \mathrm{V}$ & $\begin{array}{l}\text { Give the source of funding and the role of the funders for the } \\
\text { present study. }\end{array}$ & 15 \\
\hline
\end{tabular}

\section{References}

1. Mizoguchi, F.; Slowikowski, K.; Wei, K.; Marshall, J.L.; Rao, D.A.; Chang, S.K.; Nguyen, H.N.; Noss, E.H.; Turner, J.D.; Earp, B.E.; et al. Functionally distinct disease-associated fibroblast subsets in rheumatoid arthritis. Nat. Commun. 2018, 9. [CrossRef] [PubMed]

2. Blavnsfeldt, A.B.G.; de Thurah, A.; Thomsen, M.D.; Tarp, S.; Langdahl, B.; Hauge, E.M. The effect of glucocorticoids on bone mineral density in patients with rheumatoid arthritis: A systematic review and meta-analysis of randomized, controlled trials. Bone 2018, 114, 172-180. [CrossRef] [PubMed]

3. Scott, D.L.; Wolfe, F.; Huizinga, T.W. Rheumatoid arthritis. Lancet 2010, 376, 1094-1108. [CrossRef]

4. Kitas, G.D.; Gabriel, S.E. Cardiovascular disease in rheumatoid arthritis: state of the art and future perspectives. Ann. Rheum. Dis. 2010, 70, 8-14. [CrossRef]

5. Smith, J. Primary care: Balancing health needs, services and technology. Int. J. Integr. Care 2001, 1, e36. [CrossRef]

6. Green, L.A.; Fryer, G.E.; Yawn, B.P.; Lanier, D.; Dovey, S.M. The Ecology of Medical Care Revisited. N. Engl. J. Med. 2001, 344, 2021-2025. [CrossRef] 
7. Goldenberg, D.L. The Primary Care Provider's Role in Diagnosing and Treating Rheumatoid Arthritis. Pract. Pain Manag. 2017, 17,5 .

8. Heidari, B. Rheumatoid Arthritis: Early diagnosis and treatment outcomes. Casp. J. Intern. Med. 2011, 2, 161-170.

9. Finckh, A. Early inflammatory arthritis versus rheumatoid arthritis. Curr. Opin. Rheumatol. 2009, 21, 118-123. [CrossRef]

10. Abbasgholizadeh Rahimi, S.; Légaré, F.; Sharma, G.; Archambault, P.; Zomahoun, H.; Chandavong, S.; Rheault, N.; Wong, S.T.; Langlois, L.; Couturier, Y.; et al. Application of Artificial Intelligence in Community-Based Primary Health Care: Systematic Scoping Review and Critical Appraisal. J. Med. Internet Res. 2021, 23. [CrossRef]

11. Salmeron, J.L.; Rahimi, S.; Navali, A.; Sadeghpour, A. Medical diagnosis of Rheumatoid Arthritis using data driven PSO-FCM with scarce datasets. Neurocomputing 2017, 232, 104-112. [CrossRef]

12. Morita, K.; Tashita, A.; Nii, M.; Kobashi, S. Computer-aided diagnosis system for Rheumatoid Arthritis using machine learning. In Proceedings of the 2017 International Conference on Machine Learning and Cybernetics (ICMLC), Ningbo, China, 9-12 July 2017. [CrossRef]

13. Singh, S.; Kumar, A.; Panneerselvam, K.; Vennila, J.J. Diagnosis of Arthritis through Fuzzy Inference System. J. Med. Syst. 2010, 36, 1459-1468. [CrossRef]

14. Montejo, L.D.; Jia, J.; Kim, H.K.; Netz, U.J.; Blaschke, S.; Muller, G.A.; Hielscher, A.H. Computer-aided diagnosis of rheumatoid arthritis with optical tomography, Part 1: Feature extraction. J. Biomed. Opt. 2013, 18, 076001. [CrossRef]

15. Duda, R.O.; Hart, P.E.; Stork, D.G. Pattern Classification, 2nd ed.; Wiley-Interscience: Hoboken, NJ, USA, 2000. [CrossRef]

16. Kolahdoozi, M.; Amirkhani, A.; Shojaeefard, M.H.; Abraham, A. A novel quantum inspired algorithm for sparse fuzzy cognitive maps learning. Appl. Intell. 2019, 49, 3652-3667. [CrossRef]

17. Kosko, B. Fuzzy cognitive maps. Int. J. Man-Mach. Stud. 1986, 24, 65-75. [CrossRef]

18. Tolman, E.C. Cognitive maps in rats and men. Psychol. Rev. 1948, 55, 189-208. [CrossRef]

19. Salmeron, J.L.; Mansouri, T.; Moghadam, M.R.S.; Mardani, A. Learning Fuzzy Cognitive Maps with modified asexual reproduction optimisation algorithm. Knowl.-Based Syst. 2019, 163, 723-735. [CrossRef]

20. Bueno, S.; Salmeron, J.L. Benchmarking main activation functions in fuzzy cognitive maps. Expert Syst. Appl. 2009, 36, 5221-5229. [CrossRef]

21. Stach, W.; Pedrycz, W.; Kurgan, L.A. Learning of Fuzzy Cognitive Maps Using Density Estimate. IEEE Trans. Syst. Man Cybern. Part B Cybern. 2012, 42, 900-912. [CrossRef]

22. Salmeron, J.L. Fuzzy cognitive maps for artificial emotions forecasting. Appl. Soft Comput. 2012, 12, 3704-3710. [CrossRef]

23. Kennedy, J.; Eberhart, R. Particle swarm optimization. In Proceedings of the ICNN'95-International Conference on Neural Networks, Perth, Australia, 27 November-1 December 1995; Volume 4, pp. 1942-1948. [CrossRef]

24. Lahmiri, S. Minute-ahead stock price forecasting based on singular spectrum analysis and support vector regression. Appl. Math. Comput. 2018, 320, 444-451. [CrossRef]

25. Jana, G.; Mitra, A.; Pan, S.; Sural, S.; Chattaraj, P.K. Modified Particle Swarm Optimization Algorithms for the Generation of Stable Structures of Carbon Clusters, $\mathrm{Cn}(\mathrm{n}=3-6.10)$. Front. Chem. 2019, 7. [CrossRef] [PubMed]

26. Hu, H.; Wang, H.; Bai, Y.; Liu, M. Determination of endometrial carcinoma with gene expression based on optimized Elman neural network. Appl. Math. Comput. 2019, 341, 204-214. [CrossRef]

27. Papageorgiou, E.; Stylios, C.; Groumpos, P. Fuzzy Cognitive Map Learning Based on Nonlinear Hebbian Rule. In Lecture Notes in Computer Science; Springer: Berlin/Heidelberg, Germany, 2003; pp. 256-268. [CrossRef]

28. Salmeron, J.L.; Ruiz-Celma, A.; Mena, A. Learning FCMs with multi-local and balanced memetic algorithms for forecasting industrial drying processes. Neurocomputing 2017, 232, 52-57. [CrossRef]

29. Han, K.H.; Kim, J.H. Quantum-inspired evolutionary algorithm for a class of combinatorial optimization. IEEE Trans. Evol. Comput. 2002, 6, 580-593. [CrossRef]

30. Moons, K.G.M.; Altman, D.G.; Reitsma, J.B.; Ioannidis, J.P.A.; Macaskill, P.; Steyerberg, E.W.; Vickers, A.J.; Ransohoff, D.F.; Collins, G.S. Transparent Reporting of a multivariable prediction model for Individual Prognosis or Diagnosis (TRIPOD): explanation and elaboration. Ann. Intern. Med. 2015, 162, W1-W73. [CrossRef]

31. Rahimi, S.A.; Jamshidi, A.; Ruiz, A.; Ait-kadi, D. A new dynamic integrated framework for surgical patients' prioritization considering risks and uncertainties. Decis. Support Syst. 2016, 88, 112-120. [CrossRef]

32. Löfgren, M.; Opava, C.H.; Demmelmaier, I.; Fridén, C.; Lundberg, I.E.; Nordgren, B.; Kosek, E. Pain sensitivity at rest and during muscle contraction in persons with rheumatoid arthritis: a substudy within the Physical Activity in Rheumatoid Arthritis 2010 study. Arthritis Res. Ther. 2018, 20. [CrossRef]

33. Mok, C.C. Morning Stiffness in Elderly Patients with Rheumatoid Arthritis: What is Known about the Effect of Biological and Targeted Agents? Drugs Aging 2018, 35, 477-483. [CrossRef]

34. West, S. Rheumatology Secrets E-Book; Elsevier Health Sciences: Amsterdam, The Netherlands, 2019.

35. McWilliams, D.F.; Walsh, D.A. Pain mechanisms in rheumatoid arthritis. Clin. Exp. Rheumatol. 2017, 35, 94-101.

36. Marhadour, T.; Jousse-Joulin, S.; ChalèS, G.; Grange, L.; Hacquard, C.; Loeuille, D.; Sellam, J.; Albert, J.D.; Bentin, J.; Valckenaere, I.C.; et al. Reproducibility of Joint Swelling Assessments in Long-lasting Rheumatoid Arthritis: Influence on Disease Activity Score-28 Values (SEA-Repro Study Part I). J. Rheumatol. 2010, 37, 932-937. [CrossRef]

37. Isiksacan, Z.; Erel, O.; Elbuken, C. A portable microfluidic system for rapid measurement of the erythrocyte sedimentation rate. Lab Chip 2016, 16, 4682-4690. [CrossRef] 
38. Stach, W.; Kurgan, L.; Pedrycz, W.; Reformat, M. Genetic learning of fuzzy cognitive maps. Fuzzy Sets Syst. 2005, 153, 371-401. [CrossRef]

39. Sierra, M.R.; Coello Coello, C.A. Improving PSO-Based Multi-objective Optimization Using Crowding, Mutation and $\epsilon$ Dominance. In Evolutionary Multi-Criterion Optimization; Coello Coello, C.A., Hernández Aguirre, A., Zitzler, E., Eds.; Springer: Berlin/Heidelberg, Germany, 1995; pp. 505-519.

40. Wang, L. (Ed.) Support Vector Machines: Theory and Applications; Springer: Berlin/Heidelberg, Germany, 2005. [CrossRef]

41. Han, K.H.; Kim, J.H. Quantum-Inspired Evolutionary Algorithms with a New Termination Criterion, $H_{\epsilon}$ Gate, and Two-Phase Scheme. IEEE Trans. Evol. Comput. 2004, 8, 156-169. [CrossRef]

42. Lv, F.; Yang, G.; Yang, W.; Zhang, X.; Li, K. The convergence and termination criterion of quantum-inspired evolutionary neural networks. Neurocomputing 2017, 238, 157-167. [CrossRef]

43. Diri, B.; Albayrak, S. Visualization and analysis of classifiers performance in multi-class medical data. Expert Syst. Appl. 2008, 34, 628-634. [CrossRef]

44. Silveira, I.G.; Burlingame, R.W.; von Mühlen, C.A.; Bender, A.L.; Staub, H.L. Anti-CCP antibodies have more diagnostic impact than rheumatoid factor (RF) in a population tested for RF. Clin. Rheumatol. 2007, 26, 1883-1889. [CrossRef] 